\section{A seleção do modo verbal em orações completivas do português*}

\section{Mood selection in Portuguese complement clauses}

Paulo Mosânio Teixeira DUARTE (in memoriam) Maria Claudete LIMA (UFC) claudete@ufc.br

Recebido em: 15 de maio de 2019. Aceito em: 05 de out. de 2019.

*Este artigo apresenta os resultados de uma pesquisa sobre o emprego do modo verbal realizada de 2002 a 2005, na Universidade Federal do Ceará. O projeto, coordenado pelo Prof. Paulo Mosânio, teve como membro, além do segundo autor deste artigo, um bolsista PIBIC/CNPq, que esteve vinculado ao projeto por poucos meses, período em que coletou parte das ocorrências. Este trabalho, produzido preliminarmente antes de 2018, toma por base o relatório final do projeto, escrito pelos autores, e apresentado ao Departamento de Letras Vernáculas em março de 2005. A apresentação tardia, em uma publicação póstuma, é uma forma de a coautora prestar homenagem ao autor principal.

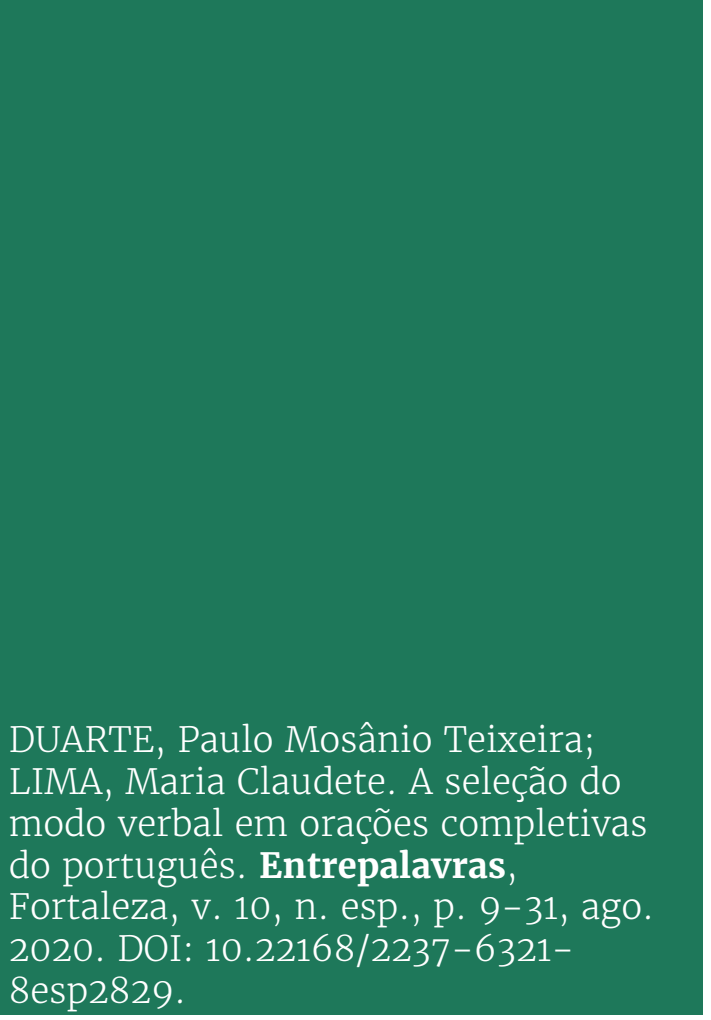

Resumo: A seleção do modo verbal, a despeito das inúmeras pesquisas sobre o tema, permanece um desafio à descrição linguística, especialmente em contextos em que o indicativo alterna com o subjuntivo. Neste trabalho, analisam-se ocorrências de orações completivas introduzidas por que, retiradas de um corpus do português culto falado em Fortaleza, com o fim de investigar os fatores sintático-semânticos que podem influenciar a escolha do modo da subordinada. Baseados em Bybee e Terrell (1990) e Pottier (1992), faz-se uma pesquisa quanti-qualitativa, que revelou serem as variáveis valor semântico e tipo de oração as mais significantes estatisticamente. Quanto ao valor semântico do verbo ou estrutura predicadora (SER + adj) da oração matriz, o indicativo predomina em todas as classes, com exceção do valor de desejo/intenção, em que o subjuntivo é o mais frequente tanto na direção da função para a forma, quando da forma para a função. Quanto ao tipo de oração, há maior frequência de subjuntivo nas orações objetivas indiretas. A predominância do indicativo sobre o subjuntivo parece se dever à tendência de não codificação gramatical da subjetividade em contextos em que o sentido subjetivo é previsível, como resultado da atuação do princípio da economia.

Palavras-chave: Subjuntivo. Oração completiva. Linguística Cognitivo-funcional. 
v. 10 (esp)

9-31

ago.

2020

Abstract: Mood selection, despite the numerous researches on the topic, remains a challenge to the linguistic description, especially, in contexts where the indicative alternates with the subjunctive. In this work, we analyze the occurrences of completive clauses introduced by que, taken from a corpus of Portuguese spoken in Fortaleza, to investigate the syntactic-semantic factors that may influence the choice of the subordinate's mood. Based on Bybee and Terrell (1990), and Pottier (1992), we carried out quantitative-qualitative research, which revealed that semantic value and type of sentence are the most statistically significant variables. As for the semantic value of verb or structure "is $X^{\text {adj" }}$ of the matrix clause, the indicative predominates in all classes except for the desire/intention value, in which the subjunctive is the most frequent both from function to form when from form to function. As for the type of sentence, there is a higher frequency of subjunctive in indirect objective sentences. The predominance of the indicative over the subjunctive seems to be due to the tendency to zero grammatical coding in contexts that subjective sense is predictable, as a result of the economic principle.

Keywords: Subjunctive. Completive clause. Cognitive-functional Linguistics.

\section{Introdução}

$\mathrm{Na}$ tradição gramatical, os modos verbais indicativo e subjuntivo são descritos em termos de oposição certeza/incerteza, realidade/irrealidade (CUNHA, 1983; BECHARA, 1999). Essa descrição, para além do problema de se basear em categorias semânticas que não estão bem definidas, não se coaduna com o efetivo emprego dos modos, como ilustram as frases abaixo, em que há o uso do indicativo, mas a certeza não se faz presente em todos os períodos ${ }^{1}$.

(1) Com certeza ela sentiu na pele (CP-BR-O Nortão-2019) ${ }^{2}$

(2) Provavelmente ele sentiu alguma coisa e pediu para ela não ir (CP-BR-Terra=2019) ${ }^{3}$

(3) ...possivelmente ela se sentiu mal por um problema dos nervos (CP-BR-Tv Prime-2019) 4

O mesmo acorre no nível do período composto, em que o uso do indicativo ou do subjuntivo contraria o definido pela gramática, como vemos em (4) e (5).

\footnotetext{
${ }^{1}$ As ocorrências (1) a (5) foram retiradas do Corpus do Português, aba Now (2019): www. corpusdoportugues.org

${ }^{2}$ http://www.onortao.com.br/noticias/chifres-me-trouxeram-musicas-diz-nova-cantora-sertanejanaiara-azevedo,65822.php

3 https://noticias.terra.com.br/brasil/cidades/tragedia-em-santa-maria/garota-que-desistiude-ir-a-boate-kiss-morre-em-acidente-no-pr,78d88a3dgf9ac310VgnVCM5000009ccceboaR CRD.html
}

4 https://www.tvprime.com.br/noticia/12368/televisao/cantora-sofre-isquemia-cerebral-e-desmaiaem-programa-de-tv-ao-vivo-27092019 
(4) Parece que Henrique está mesmo apaixonado (CP-BRBlasting News-2019) $)^{5}$

(5) Lamento que esteja sendo mais uma vez vítima de calúnias (CP-BR-Folha-2019) ${ }^{6}$

No primeiro exemplo, não há exatamente certeza. Na perspectiva do falante, o fato expresso na subordinada é encarado como aparente, mas o verbo assume a forma do indicativo. No segundo, o estado de coisas expresso na subordinada é real, mas o verbo assume a forma do subjuntivo.

Outro uso que merece ser investigado é a alternância que ocorre especialmente em determinadas classes de verbos com semântica de julgar, como pensar, supor, achar, que ora levam o verbo da subordinada para o subjuntivo, ora para o indicativo. Cabe investigar se, com esses verbos, o uso do subjuntivo é estatisticamente predominante. Em segundo lugar, se há uma motivação semântica e/ou discursiva, para um e outro emprego. Haveria, como afirmam alguns gramáticos, que insistem na oposição entre os dois modos verbais, no indicativo, um grau de certeza maior do que aquele detectado no emprego do subjuntivo? Relacionados a este estudo, em que está em jogo o caráter assertivo do verbo da oração principal7 , outras incursões se fazem necessárias, considerados outros valores semânticos ligados à oração: ordem, proibição, apreciação, negação, entre outros.

O modo verbal é, portanto, muito mais complexo do que faz crer a tradição gramatical e algumas obras pautadas por um estruturalismo simplificador, como o de Llorach (1981), que procura tratar do assunto em termos binaristas. Muitas pesquisas têm demonstrado essa complexidade, especialmente, em termos da alternância, a maioria de cunho sociolinguístico, como os trabalhos de Alves Neta (2000), Carvalho (2007), Meira (2006) e, mais recentemente, Carvalho, Araújo e Nascimento Neto (2017), Pimpão (2017), Luchesi e Meira (2019) e Souza e Oliveira (2020).

\footnotetext{
5 https://br.blastingnews.com/tv-famosos/2016/09/resumo-de-abismo-de-paixao-08-09-elisadescobre-que-foi-ingrid-que-atirou-em-ramiro-001105421.html

${ }^{6}$ https://www1.folha.uol.com.br/poder/2018/05/pf-diz-que-gleisi-recebeu-mais-de-r-13-milhaoem-propina-e-caixa-dois.shtml

7 O conceito de oração principal adotado neste trabalho é o tradicional, ou seja, fragmento do período subordinado que tem como um de seus actantes/circunstantes uma outra oração, chamada de oração subordinada. A noção de principal adotada por Perini (1995) e Bechara (1999), embora bem fundamentada estruturalmente, não foi cogitada neste trabalho, por sua inaplicabilidade.
} 
10 (esp)

9-31

ago.

2020

Este trabalho visa investigar os fatores sintático-semânticos que podem influenciar a escolha do modo da subordinada. Pela impossibilidade de verticalizar o estudo do modo no âmbito das orações completivas, adverbiais e relativas, restringimo-nos ao emprego do modo nas orações completivas. Nosso objetivo central é investigar a influência semântico-discursiva do verbo da oração principal no emprego do modo da oração subordinada completiva. Para tanto, analisaremos, em corpus de língua culta falada em Fortaleza, o vínculo entre as noções semânticas de asserção, apreciação, desejo, ato mental, dúvida e ordem e a escolha do modo nas orações completivas, iniciadas por que, e a relação entre o emprego do modo e os fatores idade e registro.

\section{Modo e modalidade}

Na tradição gramatical, o estudo do modo em português limita-se à oferta de paradigmas verbais e à listagem de valores das formas verbais. O modo indicativo é considerado o modo da certeza; o subjuntivo, do desejo ou da dúvida e o imperativo, da ordem. Como já assinalamos, esta relação entre forma e sentido não é absoluta. Camara Jr. (1999) mostra que o indicativo, como forma não marcada, atinge a área dos outros modos, como mostra o emprego do futuro do indicativo, por exemplo, para indicar dúvida - Onde andará o meu amor, agora? -, ou ordem - Honrarás pai e mãe. Para o autor, o subjuntivo, como o imperativo, é uma forma marcada na categoria de modo que "assinala uma tomada de posição subjetiva do falante em relação ao processo verbal comunicado" (CAMARA JR., 1999, p.98). O quadro 1 resume a proposta do autor quanto à categoria de modo.

Quadro 1 - Modo verbal, conforme Camara Jr. (1999)

\begin{tabular}{|l|c|c|}
\hline modo & Posição subjetiva & Dependência sintática \\
\hline indicativo & - & - \\
\hline subjuntivo & + & + \\
\hline imperativo & + & - \\
\hline \multicolumn{2}{|l|}{ Fonte: elaborado pelos autores. }
\end{tabular}

Por muitas vezes ser usado em orações subordinadas obrigatoriamente, Camara Jr. (1999) considera que o emprego do subjuntivo seria mera servidão gramatical, ou seja, manifestação formal sem correlato semântico. Nesse caso, segundo Lyons (1995), não caberia falar em modo, pois não haveria contraste entre as formas 
indicativo e subjuntivo. Só seria modal o contraste entre uma forma A e B em dada língua que atendesse a uma dessas condições: (1) as formas estão em distribuição complementar de tal modo que o uso de um contrasta semanticamente com o do outro, como em orações absolutas em português: Deus te guarda/Deus te guarde; e (2) a ocorrência das formas se correlaciona com uma diferença de modalidade que está marcada em algum lugar na frase, como em Ele crê que ela vem/Ele não crê que ela venha. Quando o subjuntivo for exigido sintaticamente, sem correlação com a modalidade da frase, como em Embora seja inteligente, saiu-se mal na prova, não se poderia falar em contraste de modo.

Essa também é a lição corrente na tradição de outras línguas românicas, como mostram Bybee e Terrell (1990) a respeito do espanhol. Segundo os autores, a análise mais comum do uso do subjuntivo nas orações subordinadas considera que o subjuntivo não tem nenhuma função semântica, figuraria apenas por uma relação de coocorrência, isto é, o subjuntivo seria empregado apenas por restrições sintáticas, como em português diante de conectivos concessivos como embora, ainda que etc.

Em relação ao espanhol, Bybee e Terrell (1990) se contrapõem a esta descrição sintática do modo, em que o uso é determinado pela oração principal, e consideram que o modo da oração subordinada é escolhido livremente pelo falante conforme sua atitude perante a proposição. A distribuição dos modos subjuntivo e indicativo em espanhol dependeria da noção semântica da frase, como ilustra o Quadro 2, adaptado de Bybee e Terrell (1990, p. 153).

Quadro 2 - Relação entre noção e modo (BYBEE; TERRELL, 1990)

\begin{tabular}{|l|l|l|}
\hline Noção & Classe & Modo \\
\hline Asserção & Asserção & Indicativo \\
& Informe & Indicativo \\
\hline Pressuposição & Ato mental & Indicativo \\
& Comentário & Subjuntivo \\
\hline Nem asserção nem pressuposição & Dúvida & Subjuntivo \\
& Ordem & Subjuntivo \\
\hline
\end{tabular}

Fonte: adaptado de Bybee e Terrell (1990, p.153).

Os autores concluem que a área da pressuposição intermediária seria uma zona de instabilidade no sistema de modo, o que se evidencia pela alternância indicativo/subjuntivo com uma tendência maior de uso daquele que deste. 
10 (esp)

9-31

ago.

2020

Entendendo a gramática como uma abstração da experiência humana, Pottier (1992) organiza as modalidades em torno do EU: alética, a independência do EU, orientada para o possível e o necessário; epistêmica, o pensamento do EU, orientada para a percepção: o saber e o crer; factual, o fazer do EU, ou seja, o EU fala de suas intenções em relação ao fazer e ao dizer, em que entra o poder e o dever; e axiológica, o julgamento do EU em relação ao que enuncia, em que entram o querer e o valer.

As modalidades se organizam em eixos contínuos. A epistêmica, por exemplo, pode ir do imaginar ao saber como extremos, tendo como intermediários pensar e crer. O factual vai do querer ao agir, passando pelo poder e pelo dever (CARREIRA, 1996). As modalidades se combinam no que o autor chama de percursos mentais complexos. A modalidade axiológica, por exemplo, pode se combinar com a factual e um DEVER transforma-se em VALER: É bom que faças isso.

Em Bybee e Terrell (1990), a combinação é tratada como ambiguidade. Os autores exemplificam várias possibilidades de dupla leitura com frases que podem ser interpretadas como informação ou ordem, informação ou comentário, asserção ou dúvida, comentário ou ordem etc. A frase É bom que faças isso, por exemplo, poderia ser interpretada como uma opinião (comentário na nomenclatura usada por BYBEE; TERRELL, 1990; axiológica, segundo POTTIER, 1992) ou como uma ordem (factual, segundo POTTIER, 1992).

No que diz respeito especificamente ao uso do subjuntivo em português, vários estudos (ALVES NETA, 2000; CARVALHO, 2007; MEIRA, 2006) com dados de fala mostram a predominância do indicativo e o uso do subjuntivo relacionado a contextos de subordinação. Mais recentemente, Carvalho, Araújo e Nascimento Neto (2017) analisaram o emprego do presente do subjuntivo em alternância com o presente do indicativo em orações substantivas e orações com talvez nos dados do PORCUFORT, o mesmo banco que analisamos nesta pesquisa, e chegaram à conclusão de que o subjuntivo é empregado categoricamente em orações completivas com verbos matrizes não factivos volitivos (querer, gostar) e predominantemente com verbos bicondicionais de possibilidade (ser possível, pode ser). Com verbos de opinião, os autores encontraram alternância subjuntivo/indicativo e com verbos factivos, como saber, predominância de indicativo.

Outro trabalho recente que discute o emprego do modo em português é o de Pimpão (2017), que retoma resultados de pesquisas 
anteriores (PIMPÃO, 1999, ALMEIDA, 2010, MEIRA, 2006; CARVALHO, 2007), sobre o emprego do subjuntivo no Sul, Sudeste e Nordeste do Brasil como evidências de que o subjuntivo é empregado em contextos de projeção futura e de pressuposição. Nos dados discutidos pela autora, os índices de emprego do subjuntivo em contexto de projeção temporal futura variaram de $76 \%$ a $98 \%$.

Diferentemente de Carvalho, Araújo e Nascimento Neto (2017) que estudaram apenas as substantivas, Pimpão (2017) não fez distinção do tipo de subordinada e abordou tanto as substantivas, como as relativas e as adverbiais. Restringindo-se apenas às adverbiais, Luchesi e Meira (2019) estudam a variação do subjuntivo no português popular do interior da Bahia. Os dados, de falantes com pouca ou nenhuma escolaridade da sede e da zona rural do município baiano de Santo Antônio de Jesus, mostraram uma tendência ao uso do subjuntivo em orações condicionais: 69\% (352/513) e em orações com localização temporal anterior $87,1 \%(115 / 132)$ ou posterior à fala $79,2 \%(346 / 437)$, corroborando, de certo modo, os resultados de Pimpão (2017).

Também estudaram dados do português rural, Souza e Oliveira (2020), que tomaram como corpus amostras de fala de duas comunidades quilombolas do interior da Bahia: Montevidinha e Rio das Rãs. Os autores, que, como Pimpão (2017), analisaram completivas, relativas e adverbiais, encontraram valores muito próximos de frequência de indicativo e subjuntivo no geral: 52,5\% (380/724) e $47,5 \%(344 / 724)$, respectivamente. As três variáveis que se mostraram mais relevantes nesse estudo foram, em ordem decrescente, o tempo verbal da subordinada e o tipo de verbo da matriz, seguido do tipo de oração subordinada. Quanto à primeira, dos dois tempos avaliados, o presente e o pretérito, os dados mostraram uma tendência ao uso do indicativo com o presente - 91,2\% (197/216) - e ao uso do subjuntivo com o pretérito: $63,9 \%$ (325/508). Quanto ao tipo de verbo, os autores encontraram 100\% (113/113) de indicativo com verbos cognitivos (foram inclusos nesta categoria verbos de opinião como achar). Com verbos volitivos, similarmente à pesquisa de Carvalho, Araújo e Nascimento Neto (2017), e com verbos dicendi, a predominância foi do subjuntivo: $72,7 \%(56 / 77)$ e $65,7 \%$ (25/38), respectivamente.

Quanto à terceira variável selecionada como estatisticamente significante em Souza e Oliveira (2020), as orações completivas e relativas parecem ser as que mais favorecem o indicativo: 71,4\% (152/213) e 80,8\% (105/130), respectivamente. Já as orações adverbiais favorecem 
10 (esp)

9-31

ago.

2020

o emprego do subjuntivo: o indicativo foi empregado em apenas 32,3\% (123/258) das adverbiais, o que parece reforçar ser o subjuntivo mera servidão gramatical.

Os dados do português ilustrados pela maioria destas pesquisas são compatíveis com a proposta de Bybee e Terrell (1990) para o espanhol em que a pressuposição, em que entram os verbos de opinião, constitui justamente a área de instabilidade, como demonstraram a pesquisa de Carvalho, Araújo e Nascimento (2017) e Pimpão (2017). A pesquisa de Souza e Oliveira (2020) mostra certa incompatibilidade com a proposta de Bybee e Terrell (1990), por apresentar uso categórico de indicativo com o que chamaram de verbo cognitivo. Essa incompatibilidade pode ser apenas aparente porque os dados analisados em Souza e Oliveira (2020) divergem socialmente dos dados analisados em Carvalho, Araújo e Nascimento (2017). Além disso, exceto por alguns poucos exemplos com o verbo achar, não fica claro exatamente que verbos entraram na categoria cognitivo.

Verbos de volição, que apresentaram 100\% de subjuntivo nos dados de Carvalho, Araújo e Nascimento Neto (2017) e predominância de $72,7 \%$ na pesquisa de Souza e Oliveira (2020), são inclusos no valor semântico de ordem em Bybee e Terrell (1990): quiero que non quedemos un rato más (Quero que fiquemos um pouco mais), portanto, estão no campo semântico de uso do subjuntivo, no extremo do quadro 2.

Os dados apresentados justificam um estudo do modo de base essencialmente semântica, sem desconsiderar, naturalmente, outros fatores, como passamos a discutir na seção seguinte. É o que estamos propondo nesta pesquisa, pautada nos princípios da linguística cognitivo-funcional que, vendo a língua como parte da cognição humana e a gramática como emergente e simbólica, estuda os fenômenos linguísticos apenas em situações de uso.

\section{Metodologia}

Nesta pesquisa de cunho quali-quantitativo, utilizamo-nos do banco de dados Português Oral Culto de Fortaleza (PORCUFORT), organizado pelo Prof. José Lemos Monteiro, nos moldes do Projeto NURC e coletado no início dos anos 90. Esse banco de dados é composto de 62 inquéritos, divididos em: a) 13 inquéritos de diálogo entre dois informantes (D2); b) 30 inquéritos de diálogos entre informante e documentador (DID); c) 19 inquéritos de elocuções formais (EF). Os informantes, totalizando 
73, são, em sua maioria, fortalezenses ou cearenses que pouco ou nunca se afastaram do Estado. São de ambos os sexos e de diferentes faixas etárias: uma primeira, de 22 a 35 anos; uma outra, de 36 a 55 anos; e uma última, a partir de 56 anos.

Desse banco de dados, valemo-nos de uma amostra constituída de 11 inquéritos, o que totalizou 8h58minutos de gravação, distribuídas do seguinte modo:

- 3 inquéritos do registro D2, que totalizam 3 horas e 6 informantes de 3 faixas etárias diferentes:

D2-07 (60 minutos) - faixa I (mulher, 26 anos) e faixa II (mulher, 47 anos)

D2-30 (6ominutos) - faixa II (homem, 40 anos) e faixa I (mulher, 31 anos)

D2-39 (60 minutos) - faixa III (mulher, 62 anos) e faixa III (mulher, 66 anos)

- 3 inquéritos do registro DID, num total de 3 horas de gravação e 3 faixas etárias diferentes:

DID-21 (60 minutos) - faixa I (homem, 25 anos)

DID-12 (60 minutos) - faixa II (mulher, 41 anos)

DID-44 (60 minutos) - faixa III (homem, 70 anos)

- 5 inquéritos do registro $\mathrm{EF}$, num total de 2 horas e 58 minutos e informantes de 3 faixas etárias diferentes.

EF-17 (60 minutos) - faixa I (homem, 32 anos)

EF-19 (60 minutos) - faixa II (homem, 42 anos)

EF-114 (21 minutos) - faixa III (homem, 66 anos)

EF-14 (12minutos) - faixa III (homem, 66 anos)

EF-214 (25 minutos) - faixa III (homem, 57 anos)

Ressaltamos que a seleção dos inquéritos foi guiada por dois critérios: (1) a duração da gravação, de modo que somassem em torno de 3 horas de gravação de cada registro, e (2) a faixa etária, de maneira a se ter, aproximadamente, 1 h de gravação de cada uma das faixas. 0 sexo não foi um fator controlado, uma vez que a pesquisa não pretende testar hipóteses referentes a essa variável ${ }^{8}$.

${ }^{8}$ A variável sexo/gênero é discutida mesmo no âmbito de trabalhos de cunho sociolinguístico. Freitag (2015) mostra, por exemplo, como alguns resultados de pesquisas sobre a influência desta variável no comportamento linguístico são contraditórios e muitas vezes, apenas especulações. A 
v. $10(\operatorname{esp})$

9-31

ago.

2020

Selecionamos as ocorrências segundo o esquema sintático tradicional das orações completivas:
a) subjetivas;
b) predicativas;
c) objetiva direta;
d) objetiva indireta;
e) completiva nominal;
f) apositivas.

Limitamo-nos às orações subordinadas introduzidas pelos conectivos que. Excluímos, assim, pelas nossas limitações de tempo, aquelas introduzidas por se, pronomes e advérbios interrogativos.

Em cada uma das orações, partimos da natureza semântica do período, basicamente ternária, conforme proposta de Bybee e Terrell (1990, p. 153):
a) asserção;
b) pressuposição;
c) nenhuma das duas.

Com base no quadro proposto por Bybee e Terrell (1990, p.147157) e Bosque (1990), conjugado ao parâmetro tipo de oração subordinada, eram estas as nossas hipóteses:

a) a asserção, em qualquer de suas subclasses, leva o verbo para o indicativo;

b) se a pressuposição se traduz na classe de ato mental, o verbo vai para o indicativo;

c) se a pressuposição se traduz na classe de comentário, o verbo vai para o subjuntivo;

d) dúvida e ordem impõem o uso do subjuntivo.

A análise preliminar dos dados mostrou, todavia, que os fatores acima eram insuficientes para categorizar todas as ocorrências. A pressuposição, por exemplo, relacionada ao valor semântico da oração subordinada, mostrou-se limitada por aplicar-se apenas a frases como

autora afirma que muitos resultados apontados como resultantes da variável sexo/gênero podem ter relação com outro fator, como a mobilidade social, por exemplo. Outro problema ainda diz respeito à variável em si: sexo ou gênero? No caso do PORCUFORT, corpus coletado com formulário binário, não haveria condições de avaliar o gênero, apenas o sexo biológico que, por si, não deve influenciar a escolha do modo da oração subordinada. Se o corpus permitisse, um possível fator a ser testado quanto à influência da escolha seria a escolaridade, mas todos os falantes são de nível superior. Por todas essas razões, avaliam-se nesta pesquisa apenas as variáveis registro e idade. 
lamento que ela não esteja disponível, em que o conteúdo da subordinada é pressuposto. Já o uso do subjuntivo em frases como é bom que ela esteja disponivel, que parece ser semelhante ao da frase anterior, não pode ser colocado na mesma categoria, pois o conteúdo da subordinada pode ser ou não pressuposto. Isso nos levou a propor uma categoria semântica mais abrangente e relacionada à modalidade da oração principal: apreciação (CERVONI, 1989; POTTIER, 1992), embora estejamos a par do problema que acarreta no seio de uma teoria das modalidades. Com esta categoria, tanto frases com estruturas do tipo lamento que, como frases com estruturas predicadoras ser + adjetivo, do tipo é lamentável, é necessário, é claro, é evidente ficarão no mesmo grupo. Tal observação nos obrigou a rever as categorias semânticas do verbo ou do predicador SER ADJ da matriz inicialmente propostas e a propor novas categorias antes de proceder à análise semântica dos dados:

a) desejo ou intenção: codificados por verbos volendi, como querer, desejar, gostar (no futuro do pretérito) etc.

b) diretividade: expressa por verbos como fazer (que), convencer (a), persuardir (a), levar (a), os quais mudam a conduta do ouvinte ou pretendem mudar pela ordem (função conativa).

c) asserção: manifesta-se pela ampla gama de verba dicendi (afirmar, dizer, contar).

d) ato mental: expresso por verbos cujos sujeitos sejam experienciadores, como os de processos mentais (imaginar, pensar, ver, perceber etc), sensoriais/perceptuais (ver, ouvir).

e) apreciação: codificada por verbos de julgamento subjetivo como achar, julgar, pensar e outros como lamentar, convir, basta, interessar, duvidar, precisar, necessitar os quais parecem guardar fronteira relativa com a asserção e o ato mental. A diferença é que neles a subjetividade aflora, a nosso ver, de maneira mais nítida.

Deste modo, apresentamos um quadro mais exequível para nossa análise. Descartamos a teoria das modalidades, em sua amplitude, por vários motivos, entre os quais:

a) a análise resultaria complicada;

b) não há uma teoria consensual das modalidades;

c) aflora muito nítido que há um trânsito muito grande entre as categorias modais; 
v. 10 (esp)

9-31

ago.

2020

Estamos conscientes de que mesmo os elementos linguísticos podem ser associados a uma ou outra das categorias adotadas por nós. Assim, um querer pode implicar uma diretividade. Alguns verbos de apreciação podem ser listados entre os de ato mental, mas alocálos aí não expurgaria a interface. Adicionalmente, convém esclarecer que as modalidades não-apofânticas de discurso podem interferir, a exemplo da interrogação. Deixamos, contudo, esse dado para a análise qualitativa, para não colocar fator dissonante.

As ocorrências foram coletadas manualmente, na versão escrita do corpus, pelo bolsista do projeto, no período correspondente à sua participação (set/2002 a mar/2003) ${ }^{9}$. Em seguida, procedeu-se à revisão e à digitação dos dados coletados por ele para posterior análise dos dados, que foi precedida de categorização e tratamento estatístico no software SPSS 7.5 for Windows.

Cada ocorrência foi analisada conforme os seguintes parâmetros:

a) registro: D2, DID e EF;

b) idade: faixa etária I, faixa etária II e faixa etária III;

c) tipo de oração: subjetiva, objetiva direta, objetiva indireta, predicativa, apositiva, completiva nominal;

d) valor semântico do verbo da principal: desejo ou intenção, diretividade, asserção, ato mental, apreciação;

e) advérbio modal: presente ou ausente;

f) modo da oração principal: indicativo, subjuntivo, imperativo, forma infinita, não-se-aplica ${ }^{10}$;

g) tempo da oração principal: presente, perfeito, imperfeito, futuro presente, futuro pretérito, forma infinita, forma de futuro semântico, não-se-aplica;

h) tempo da subordinada: presente, futuro, perfeito, imperfeito, mais-que-perfeito, futuro pretérito;

i) forma verbal da subordinada: simples, composta com auxiliar modal, composta com modal;

j) lexias e construções sintáticas: achar, dizer, desejar, é $X^{\text {adj }} q u e$, entre outras.

\footnotetext{
${ }^{9}$ Reforçamos que, embora os resultados desta pesquisa estejam sendo apresentados tardiamente, continuam válidos porque o corpus em que foi baseada, coletado no início dos anos 90, continua sendo utilizado em pesquisas recentes, como em Carvalho, Araújo e Nascimento Neto (2017), por exemplo. Ademais, a temática discutida e a abordagem continuam atuais.

${ }^{10}$ Os casos de não-se-aplica de algumas variáveis constituem casos de construções em que há omissão do verbo, como em "claro que num podia chegar tarde né?" (DID-12).
} 


\section{Análise e discussão dos resultados}

Foram coletadas 566 orações completivas introduzidas pelo conectivo que nos 11 inquéritos do PORCUFORT. Os dados foram levados para o software SPSS 7.5 for Windows e categorizados, segundo os fatores listados na seção anterior.

Aplicando o teste das variáveis, as mais significantes foram o valor semântico e o tipo de oração, com grau de significância 0.000 e 0.038 , respectivamente. O tempo verbal, tanto da principal como da subordinada, não se mostrou fator relevante nos nossos dados, vez que a distribuição dos dois modos se deu de forma semelhante: predominância do indicativo com todos os tempos verbais. No caso do futuro do presente ou futuro semântico (perifrástico, ir no presente + infinitivo) na principal, o uso do indicativo foi categórico, mesmo assim foram poucas ocorrências, apenas 9, para se afirmar uma maior influência ou mesmo para se contrapor aos resultados de Pimpão (2017), que encontrou alta tendência do subjuntivo com projeção temporal futura. Quanto ao tempo da subordinada, o futuro do pretérito e o pretérito perfeito também foram usados apenas no indicativo: 22 e 54 ocorrências, respectivamente. Também esses resultados se contrapõem aos de Souza e Oliveira (2020). Mais uma vez, reforçamos que os dados são muito diferentes social e linguisticamente para uma adequada comparação.

Há predominância do modo indicativo nas duas orações $88,2 \%$ (499/566) na subordinada e 90,3\% (511/566) na matriz. Esse predomínio do indicativo, também observado em outras pesquisas, já citadas, pode dever-se à atuação do princípio da economia (HAIMAN, 1983), segundo o qual noções esperadas conforme o contexto não recebem marcação formal.

Interessante observarmos que, em 4 casos de uso de subjuntivo na matriz, o modo da subordinada se distribui igualmente entre indicativo e subjuntivo, conforme se vê na tabela 1. 
v. 10 (esp)

9-31

ago.

2020

Tabela 1 - Uso do modo nas orações matriz e subordinada

\begin{tabular}{|c|c|c|c|c|c|}
\hline & & & $\begin{array}{l}\text { Modo da } \\
\text { indicativo }\end{array}$ & $\begin{array}{l}\text { abordinada } \\
\text { subjuntivo }\end{array}$ & Total \\
\hline & indicativo & $\mathrm{N}^{\mathrm{O}}$ & 451 & 60 & 511 \\
\hline & & \% do total da subordinada & $90,4 \%$ & $89,6 \%$ & $90,3 \%$ \\
\hline & & \% do total da matriz & $88,3 \%$ & $11,7 \%$ & $100 \%$ \\
\hline & subjuntivo & $\mathrm{N}^{\mathrm{O}}$ & 2 & 2 & 4 \\
\hline & & \% do total da subordinada & $0,4 \%$ & $3,0 \%$ & $0,7 \%$ \\
\hline$\stackrel{N}{\longrightarrow}$ & & $\%$ do total da matriz & $50 \%$ & $50 \%$ & $100 \%$ \\
\hline 苂 & forma & $\mathrm{N}^{\mathrm{O}}$ & 33 & 3 & 36 \\
\hline$\pi$ & infinita & \% do total da subordinada & $6,6 \%$ & $4,5 \%$ & $6,4 \%$ \\
\hline$\frac{0}{8}$ & & $\%$ do total da matriz & $91,7 \%$ & $8,3 \%$ & $100 \%$ \\
\hline$\sum$ & imperativo & $\mathrm{N}^{\mathrm{O}}$ & 7 & 1 & 8 \\
\hline & & \% do total da subordinada & $1,4 \%$ & $1,5 \%$ & $1,4 \%$ \\
\hline & & $\%$ do total da matriz & $87,5 \%$ & $12,5 \%$ & $100 \%$ \\
\hline & não-se- & $\mathrm{N}^{\mathrm{O}}$ & 6 & 1 & 7 \\
\hline & & $\%$ do total da subordinada & $1,2 \%$ & $1,5 \%$ & $1,2 \%$ \\
\hline & & $\%$ do total da matriz & $85,7 \%$ & $14,3 \%$ & $100 \%$ \\
\hline & Total & $\mathbf{N}^{\mathbf{0}}$ & 499 & 67 & 566 \\
\hline & & \% do total da subordinada & $100 \%$ & $100 \%$ & $100 \%$ \\
\hline & & \% do total da matriz & $88,2 \%$ & $11,8 \%$ & $100 \%$ \\
\hline
\end{tabular}

Fonte: elaborada pelos autores.

A forma verbal não pareceu influir o uso do modo, já que, em todas elas, houve predominância do indicativo. Os advérbios "modais" também não se mostraram influentes no uso do modo da subordinada: quer ausentes, quer presentes, predominou o indicativo. O subjuntivo foi usado igualmente com ou sem advérbios "modais", o que mostra a não-influência de uma variável sobre a outra, em qualquer direção que se observe, pelo menos nos limites de nosso corpus.

A variável lexias e construções sintáticas, ligada ao valor semântico, se mostrou medianamente influente, uma vez que, com algumas lexias, um dos modos predominava. Por exemplo, com achar, o indicativo teve alta frequência: 97,6\% e com querer/desejar, predominou o subjuntivo: $95,6 \%{ }^{11}$. Já outros, como acreditar, talvez pelo fato de constituir um

\footnotetext{
${ }^{11}$ A aparente contradição entre nossos dados e os dados de Carvalho, Araújo e Nascimento Neto (2017) que encontraram $100 \%$ de subjuntivo com verbos de volição no mesmo banco de dados deve-se ao fato de os autores terem delimitado apenas o presente do subjuntivo, enquanto nossa pesquisa considerou todos os tempos verbais.
} 
misto de certeza com subjetividade, admitem tanto o indicativo, como o subjuntivo, embora aí haja predominância do primeiro (62,5\%). Em outros casos, o uso dos modos ficou equivalente, mas foram poucos os casos para avaliarmos a influência da variável. As lexias e construções sintáticas que admitem os dois modos verbais e a frequência numérica em cada um dos modos estão listadas na tabela 2.

Tabela 2 - Uso dos modos conforme a lexia ou construção sintática

\begin{tabular}{|c|c|c|c|c|c|}
\hline \multirow[t]{2}{*}{ lexias/construções } & \multicolumn{2}{|c|}{ indicativo } & \multicolumn{2}{|c|}{ subjuntivo } & \multirow{2}{*}{$\begin{array}{c}\text { total } \\
\mathrm{N}^{\mathrm{O}}\end{array}$} \\
\hline & $\mathrm{N}^{\mathrm{O}}$ & $\%$ & $\mathrm{~N}^{\mathrm{O}}$ & $\%$ & \\
\hline achar & 124 & 97,6 & 3 & 2,4 & 127 \\
\hline dizer/falar/contar/chamar & 142 & 98,6 & 2 & 1,9 & 144 \\
\hline pensar & 19 & 95 & 1 & 5 & 20 \\
\hline acreditar & 5 & 62,5 & 3 & 37,5 & 8 \\
\hline É X (Adj) que & 18 & 81,8 & 4 & 18,9 & 22 \\
\hline querer/gostar & 1 & 4,43 & 22 & 95,6 & 23 \\
\hline imaginar & 3 & 75 & 1 & 25 & 4 \\
\hline O/A X é que & 10 & 83,3 & 2 & 16,7 & 12 \\
\hline fazer questão/exigir & 1 & 50 & 1 & 50 & 2 \\
\hline interessar & 1 & 50 & 1 & 50 & 2 \\
\hline pedir & 1 & 50 & 1 & 50 & 2 \\
\hline Total & 325 & 88,8 & 41 & 11,2 & 366 \\
\hline
\end{tabular}

Fonte: elaborada pelos autores.

Consideramos que uma melhor avaliação da influência da variável lexia da oração principal seria possível numa ampliação do corpus e com uma recategorização das possibilidades, agrupando lexias afins, por exemplo. Num segundo momento, seria necessário revermos os casos de afastamento da maioria, a fim de verificarmos a que isto se deve. Poderíamos observar se, por exemplo, o desvio pode ser atribuído ao valor semântico da lexia no contexto. Como exemplo de uma análise mais aprofundada, tomemos o verbo pedir, de que só tivemos duas ocorrências no corpus: por que pedir em uma ocorrência figura com subjuntivo e noutra com o indicativo? Vejamos as frases (6) e (7), ambas do inquérito D2-39, informante 1.

(6) ele me pediu... que queria para a:.... pra família Dele... uma alguma dramatização::... algum trabalho pra eles fazerem mais um Natal só de de... de papai Noel 
v. 10 (esp)

9-31

ago.

2020
(7) ele:::: se diri/ me se dirigiu a mim... pedindo que eu relembrasse... o assunto da semana anterior

No primeiro caso, temos o uso do indicativo, mas o tempo verbal, um imperfeito com valor de futuro do pretérito, tem valor condicional, ligado à irrealidade, portanto ao valor semântico atribuído tradicionalmente ao subjuntivo. Além disso, o verbo pedir está no sentido de dizer: "ele disse que queria...". Esse uso é comum na fala, em que o verbo pedir é usado no sentido de perguntar e dizer, pois o complemento, ao invés de ser a objeto da solicitação, é objeto do ato de fala, como em eu pedi se ele ia sair. No exemplo em questão, a pausa nos induz a pensar na possibilidade de interpretar a subordinada como complemento de um verbo com valor de dizer.

No segundo caso, o subjuntivo condiz com o valor semântico do verbo pedir como diretividade, ligado à irrealidade.

Também ligado ao valor semântico diretividade e constante no corpus com os dois modos são as lexias exigir e fazer questão, cujas ocorrências transcrevemos a seguir.

(8) e eles fazem questão que aquela escola seja bem melhor... (DID-12)

(9) o moço lá... exigiu que eu... TInha que estar de gravata... (DID-44)

A primeira ocorrência, com o verbo da subordinada no subjuntivo, condiz com o que preceituam as normas gramaticais e com o valor semântico diretividade, que se associa ao uso tradicional do subjuntivo. Já a segunda, semanticamente semelhante à primeira, embora com outra lexia, foge ao cânon gramatical, pois o verbo está no indicativo. Não podemos aventar a hipótese de desuso do subjuntivo, porque se trata, nesse caso, de um falante de 70 anos. Ademais, ele usou o subjuntivo em três ocorrências com verbos de desejo ou intenção: querer/gostar. Parece, então, que a ausência do subjuntivo aí se deveu ao fato de a locução da subordinada já conter em si a ideia de diretividade: ter que + infinitivo. O emprego do subjuntivo seria uma redundância. Além disso, mais uma vez, a pausa pode ter influenciado o uso do modo mais comum, já que o verbo exigir ficou distante. De qualquer maneira, é bom ressaltarmos que são casos muito escassos para qualquer generalização. 
De modo geral, o indicativo foi predominante em todos os grupos, $88,2 \%$ do total de ocorrências. O subjuntivo ocorreu em percentual significativamente maior nos seguintes casos:

a) com orações objetivas indiretas $70 \%(7 / 10)$ do total de objetivas indiretas tinham o verbo no subjuntivo. No entanto, do total de ocorrências de subjuntivo, apenas 10,4\% (7/67) eram de orações objetivas indiretas. O tipo mais frequente de orações, nos dois modos, é a objetiva direta: $82 \%$ (464/566). Certamente, isto se deve ao corpus favorecer o uso de asserções e opiniões, que, no todo, propiciam o emprego do indicativo e orações objetivas diretas. A predominância de subjuntivo nas orações objetivas indiretas mostra uma relação unidirecional entre as duas variáveis, estando a objetiva indireta ligada ao emprego do subjuntivo, embora o contrário não se dê, o que indica que tal relação talvez se deva a outro fator ligado à oração objetiva indireta, provavelmente, o valor semântico.

b) valor semântico desejo ou intenção:

Neste caso, a predominância do subjuntivo ocorreu tanto na direção do sentido para a forma, ou seja, da noção de desejo ou intenção para o modo subjuntivo - 81,3\% (26/32) do total de ocorrências com valor de desejo ou intenção - como na direção da forma para o sentido, ou seja, do emprego do modo para a noção de desejo ou intenção: 38,8\% (26/67) do total de ocorrências de subjuntivo. Isso mostra uma forte relação biunívoca entre as duas variáveis, que determina a influência recíproca de uma sobre a outra: ao usarmos subjuntivo, exprimimos desejo ou intenção; ao pretendermos expressar desejo, escolhemos o subjuntivo. Tal resultado condiz com a tradição segundo a qual o subjuntivo é o modo do desejo, cabendo a esse modo o nome de optativo.

c) valor semântico apreciação/opinião:

A predominância de subjuntivo, neste caso, se deu apenas da forma para o sentido: 29,9\% (20/67) do total de ocorrências de subjuntivo. No total de ocorrências com o valor semântico de opinião (235/566), 91,5\% (215/235) tinham o verbo no indicativo e apenas 8,5\% (20/235) no subjuntivo. Entre os usos do subjuntivo, porém, esse é o segundo valor semântico mais frequente, antecedido apenas de desejo ou intenção. 
v. 10 (esp)

9-31

ago.

2020

O gráfico 1 ilustra como a tendência ao emprego do subjuntivo é maior com as orações objetivas indiretas.

Gráfico 1 - Uso do modo conforme o tipo de oração completiva

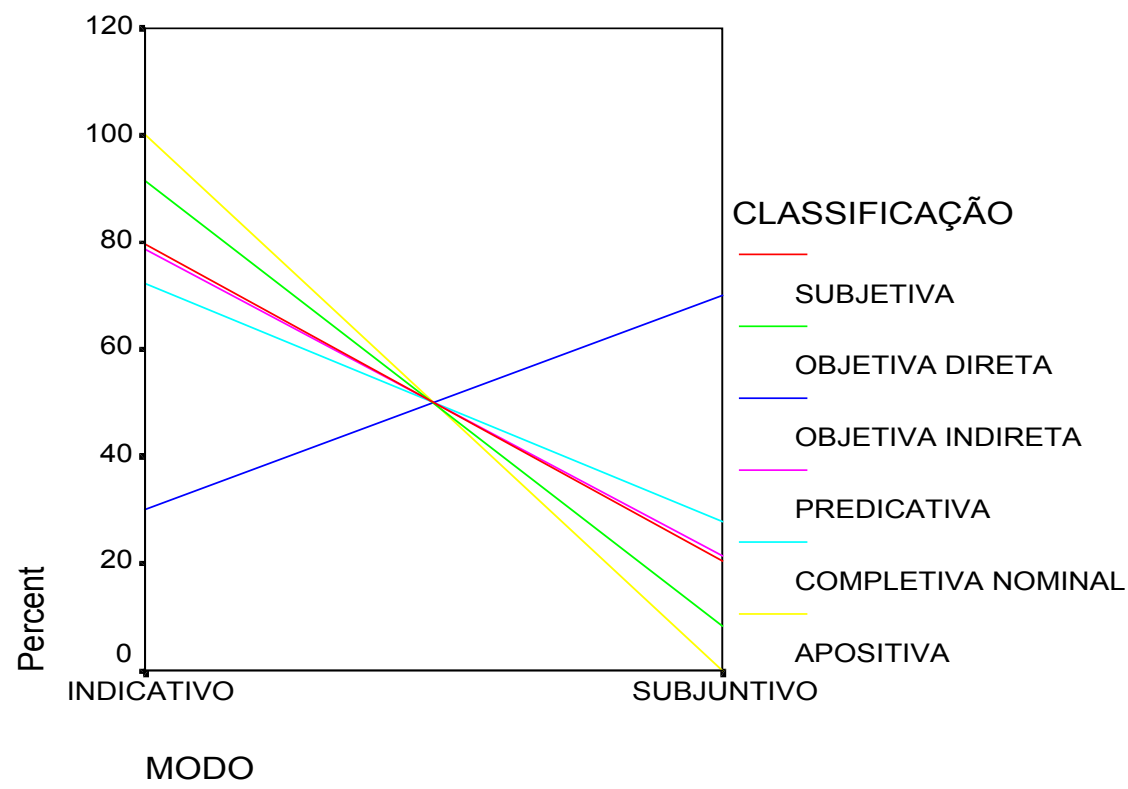

Fonte: elaborado pelos autores.

É bom chamarmos a atenção para os aparentes desvios no bojo das ocorrências com valor semântico desejo ou intenção: 6 casos de um total de 32, com lexias do tipo quer dizer que. Transcrevemos, em (10-15), as seis ocorrências:

(10) [quis dizer]que se QUALQUER um que tivesse naquele luGAR \{TAMBÉM faria um plano eleitoreiro MAS o plano É eleitoreiro (D2-30)

(11) mas eu num quero dizer que a burgueSIA... é uma questão de... Nível... intelectuAL.. (D2-30)

(12) então quer dizer que fica ... o aRRO::Z ... né?... (D2-7)

(13) eu num/tô querendo dizer ... que todo sinistro é superdotado (DID-21)

(14) MAS o que eu quero dizer pra vocês que NEsse contexto... da Revolução RUssa... os movimentos populares... eles... foram... de suma importância... para a preservação... de um objetivo comum... (EF-17)

(15) o que eu quero dizer com Isso... é que nós temos... os melhores funcionários... (EF-17) 
Não se trata exatamente de uma fórmula de desejo típica, mas de uma forma cristalizada ou lexicalizada do tipo querer dizer, em que há dissimuladamente uma asserção, ou uma explicitação em nível de metalinguagem do próprio dizer ou do dizer do outro. Trata-se de um expediente retórico, em que o querer é um mero torneio para disfarçar um dizer.

No que tange ao valor semântico apreciação, cuja tendência é o emprego do indicativo, registramos as ocorrências desviantes em $(16-34)$.

(16) mas é natural que eles num num... façam diferença num faz diferença... por quê!... qual é a diferença que existe... (D2-39)

(17) inclusive é aTÉ bom que aconteça porque o grupo não fica tão homogêneo (D2-7;79)

(18) enTÃO é interesse que... governo FAça... Reforma AGRÁria... (EF-17)

(19) se o sujeito PENsa... é bom que ele verbalize (EF-19)

(20) "... pode ser que ele nem seja eu já /tô é generalizando já /tô dizendo que é tudo veado... (D2-30)

(21) \{ele hoje / tava dizendo que::... ((ri levemente)) pode ser que depois dos noventa e cinco né? chegue a vez dele de parTIR (D2-39)

(22) pela política atual... POSSA SER que nós tenhamos... uma pessoa capaz.. (EF-17)

(23) é porque num interessa pra sociedade dominante... que que aqueles menino/ cresçam (DID-12)

(24) olha basta que eu te diga o teste dele Alice corrigiu ele tirou OIto vírgula seis em Português... (D2-7-363)

(25)NÃO BASta que HAja... apenas esse sinal de pontuação... (EF-14/70)

(26)[subentende-se] que não esteja dando aula mas / tá lotado lá (D2-7/1174)

(27) subentende-se MESmo que esteja numa unidade... (D27/1174)

(28)eu Acho que:: o que vier daqui pa/ frente (D2-30)

(29)a gente fica até pensando que toda revolução necessariamente... seja uma revolução... civil... (EF-17)

(30) eu acredito que o papai não POssa \{ir porQUE... (D2-39) 
10 (esp)

9-31

ago.

2020

(31) acredito que seja muitas matrícula né? (D2-7-335)

(32) e se Deus quiser eu num sei mais dele... acredito que esteja muito bem... (DID-12)

(33) a gente suspeita que o autismo TEnha essas características né? (DID-21)

(34) POSTUlam... QUE TENHA... HAVIdo ESTE vocábulo... faLAdo pelo povo... abantiare... (EF-214)

É digno de nota que se trata, em parte, do compromisso do sujeito com a realidade, o que pode ser constatado em lexias do tipo verdade, claro, lógico, evidente. Já o mesmo compromisso não ocorre com lexias menos assertivas e mais apreciativas, tais como, bom, natural, interessante. Isto inclui verbos como bastar, subentender, que podem ter manifestações em orações subjetivas do tipo é bastante que, fica subentendido que.

Verbos como acreditar tendem a uma certa hesitação entre indicativo e subjuntivo, embora predomine o primeiro. Sobre tais formas verbais, longas explicações foram expendidas por Bybee e Terrell (1990), mas ainda estamos longe de uma explicação satisfatória porque esta hesitação, fraca no corpus, se deve em parte a fatores semânticos ligados ao caráter fronteiriço das referidas formas verbais. O sujeito crê, e tal crença, de algum modo, é uma verdade, mas não deixa de ser uma verdade claramente subjetiva. Em termos da psicomecânica de Guillaume (1929 apud CERVONI, 1989), estamos no terreno do Possível, que indica um processo equiprovável, ou seja, algo cuja capacidade de ser é zero, está a meio caminho da atualização e da não-atualização. Uma hipótese, a ser testada em corpus mais amplo, pode assim ser formulada: se a crença incide sobre algo já ocorrido ou sobre processos dados como atemporais, a tendência é usar o indicativo, por oposição ao uso do subjuntivo, para eventos iminenciais, mas temporalmente circunstanciados.

Quanto ao registro, os dados apresentaram predominância do indicativo nos três registros. De todos os casos de subjuntivo, a maior frequência se deu no registro D2, 40\%, (27/67), seguido do registro $\mathrm{EF}, 31,3 \%$ (21/67). De qualquer modo, a variação de uso do subjuntivo entre os registros foi muito pequena para que possamos afirmar alguma influência do registro no uso do modo gramatical.

Quanto à faixa etária, houve uma predominância do indicativo nas três faixas, ressaltando-se, todavia, que, do total de usos do subjuntivo, a maioria se concentrou na faixa etária II, 38,8\% (26/67). Desse modo, os dados parecem indicar que o objeto de estudo não é 
fenômeno em estado de mudança, pois não houve variação significativa de uso nas diferentes faixas etárias.

\section{Considerações finais}

O exposto nos permite concluir, nos limites impostos pelo corpus, que o indicativo foi o modo mais empregado. O subjuntivo suplantou o indicativo apenas nos seguintes casos: (a) com orações objetivas indiretas, embora tenham sido poucas ocorrências; (b) com valor semântico de desejo ou intenção. Não podemos descartar, a título de hipótese a ser testada em outros corpora, a extensão do indicativo, pelo seu caráter de forma não marcada, porém julgamos precipitado afirmar com Perini (1995) que o subjuntivo se encontra esvaecido. Afirmar isto demandaria uma pesquisa em corpus com ampla variedade de verbos.

Do ponto de vista meramente estrutural, parece-nos precipitado afirmar que há uma tendência à servidão gramatical, considerando apenas os esquemas opositivos clássicos, que vigoram nas orações adjetivas, como em procuro alguém que sabe português/procuro alguém que saiba português. Nestas orações, a oposição entre certeza e incerteza é formalmente marcada. Não parece assistir, pois, plena razão a Said Ali (1966), que afirma a referida servidão, pelo menos como tendência, já que não podemos ter a pretendida generalização no âmbito das orações completivas, por exemplo. Isto demandaria, além da generalização, um tanto cerceada no corpus, o estudo de outras orações subordinadas: as adverbiais e as adjetivas.

O que parece viger com diversos graus de influência é o valor semântico dos verbos, o que é reconhecido pelo próprio Perini (1995). O que falta é uma oposição como esta tirada à língua latina: Socrates condemnatus est quod corrumperat iuventutem/Socrates condemnatus est quod corrumperet iuventutem (Sócrates foi condenado porque corrompera a juventude/Sócrates foi condenado porque teria corrompido a juventude). Em português, a diferença não reside entre modos verbais, porque é sempre o indicativo, enquanto em latim a diferença é de modo. Insurgimo-nos contra as posições estruturalistas de Llorach (1981) que, inspirado no formalismo glossemático, superdimensiona a oposição entre o indicativo e o subjuntivo em termos de oposições clássicas: certeza/incerteza, realidade/irrealidade.

Não queremos com isso afirmar que não existem ilhas em que vigoram valores modais como naqueles vigentes de orações 
10 (esp)

9-31

ago.

2020

predicativas, constantes de adjetivos de valor mais assertivo: certo/ errado, verdadeiro/falso, do que outros como conveniente/inconveniente, bom/mau. Do mesmo modo, podemos interpretar os verbos de querer e de ordenar como referentes ao não feito, portanto, à irrealidade, por isso a tendência para o subjuntivo.

Pelo menos provisoriamente, parece-nos lícito afirmar, cerceados, no entanto, pelas limitações do corpus, que a predominância do indicativo nos dados se deve ao princípio da economia, que funciona como deriva da língua e que leva a uma tendência não muito bem consolidada de expurgo da redundância semântica, uma vez que o contexto sintático, as lexias e os tempos verbais são esclarecedores (HAIMAN, 1983).

Isto posto, a título de arremate provisório, asseveramos que muito há que se trilhar na análise do modo. Não obstante o tamanho do corpus, os grandes tipos verbais não se encontram bem representados, vigendo os verbos de opinião. Outro ponto a destacar-se é uma abordagem das modalidades de forma a enxugá-las para um tratamento estrutural. Tais como postas em seus tipos básicos, tornariam este trabalho inviável, vez que uma mesma declaração pode ter mais de um valor modal.

Agradecimento: os autores agradecem ao então bolsista PIBIC/UFC, Alexandro Teixeira Gomes, hoje professor da Universidade Federal do Rio Grande do Norte, pela colaboração na coleta manual dos dados, primeira versão, no período de setembro de 2002 a março de 2003.

\section{Referências}

ALVES NETA, A. O uso de formas do indicativo por formas do subjuntivo no português brasileiro. Dissertação de Mestrado. Belo Horizonte: Universidade Federal de Minas Gerais, 2000.

BECHARA, E. Moderna gramática portuguesa. Rio de Janeiro: Lucerna, 1999.

BOSQUE, I. Las bases gramaticales de la alternancia modal. Repaso y balance. BOSQUE, Ignacio (ed.) Indicativo y subjuntivo. Madrid: Taurus, 1990. p.13-65.

BYBEE, J.; TERRELL, T. D. Análisis semántico del modo en español. BOSQUE, Ignacio (ed.) Indicativo y subjuntivo. Madrid:Taurus, 1990.p.145-163.

CAMARA JR., J. M. Estrutura da língua portuguesa. 30. ed. Petrópolis: Vozes, 1999.

CARREIRA, M. H. A. Pottier, B. (1992) Sémantique Générale. Paris: PUF, 237pp. DELTA: Documentação e Estudos em Linguística Teórica e Aplicada, [S.l.], v. 12, n. 1, jul. 1996. ISSN 1678-460X. Disponível em: <https://revistas. pucsp.br/delta/article/view/43817/29071>. Acesso em: 16 ago. 2020. 
CARVALHO, H. M. de. A alternância indicativo/subjuntivo nas orações substantivas em função dos tempos verbais presente e imperfeito na língua falada do Cariri. Tese de Doutorado. Programa de Pós-Graduação em Linguística. Fortaleza: Universidade Federal do Ceará, 2007.

CARVAlHO, H. M de.; ARAÚJO, A. A.; NASCIMENTO NETO, A. V. do. Uso do presente do subjuntivo em variação com o presente do indicativo no falar culto de Fortaleza. Revista (Con)textos Linguísticos (Modelos Baseados no Uso). V. 11, n.19, p. 83-103. jul. 2017.

CERVONI, J. Enunciação. São Paulo: Ática, 1989.

CUNHA, C. F. da. Gramática do português contemporâneo. Rio de Janeiro: Padrão, 1983.

FREITAG, R. M. K. (Re)discutindo sexo/gênero na sociolinguística. In: FREITAG, R. M. K.; SEVERO, C. G. (ed.). Mulheres, Linguagem e Poder Estudos de Gênero na Sociolinguística Brasileira. São Paulo: Editora Edgard Blücher, 2015. p. 17-74.

HAIMAN, J. Iconic and economic motivation. Language, 59 (4), p. 781-819, 1983.

LLORACH, E. A. Gramática estructural. Madrid: Gredos, 1981

LUCCHESI, D.; MEIRA, V. O emprego do modo subjuntivo nas orações adverbiais no português popular do interior do Estado da Bahia: um estudo sociolinguístico. DELTA, São Paulo, v. 35, n. 2, e2019350211, 2019. Disponivel em: <http://www.scielo.br/scielo.php?script=sci arttext\&pid=S0102-44502019000200410\&lng=en\&nrm=iso >. Acesso em: $\overline{10}$ ago. 2020. Epub Aug 12, 2019. https://doi.org/10.1590/1678-460x2019350211.

LYONS, J. Introduction to theoretical linguistics. 12 ed. London: Cambridge University, 1995.

MEIRA, V. 0 uso do modo subjuntivo em orações relativas e completivas no português afro-brasileiro. 2006. 317f. Dissertação (Mestrado em Letras e Linguistica) - Instituto de Letras, Universidade Federal da Bahia, Salvador, 2006.

MONTEIRO, J. L. (Org.) o português oral culto de Fortaleza - PORCUFORT. Manuscrito inédito.

PERINI, M. Gramática descritiva do português. São Paulo: Ática, 1995.

PIMPÃO, T. S. O subjuntivo não é apenas o modo da incerteza. Letrônica, v. 10, n. 1, p. 109-121, 27 dez. 2017.

POTTIER, B. Semantique générale. Paris: PUF, 1992.

SAID ALI, M. Dificuldades da língua portuguesa. Rio de Janeiro: Livraria Acadêmica, 1966.

SOUZA, M. da S.; OLIVEIRA, J. M. de. Variação do modo subjuntivo: um estudo sobre o português quilombola do interior da Bahia. A Cor das Letras. V. 21, n.1, 2020. p. 62-76, janeiro-abril de 2020. 